
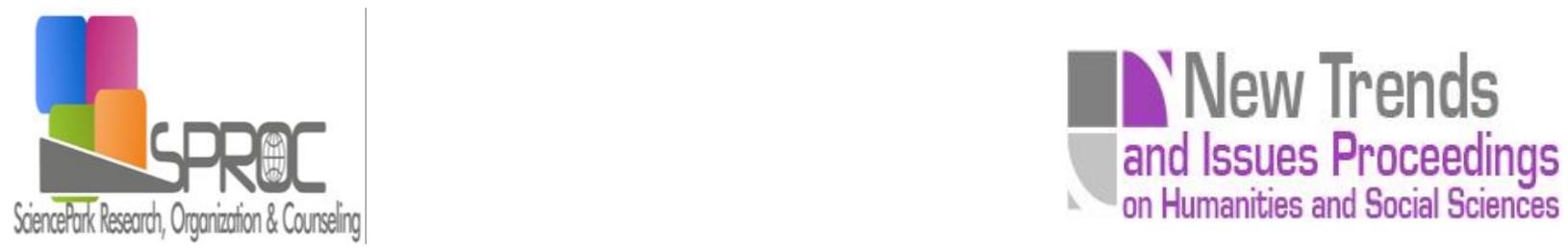

\title{
Empathy versus apathy in motivational decision making of University teachers
}

Martina Blaskova ${ }^{a}$,

Rudolf Blasko ${ }^{\mathrm{b}}$,

Suggested Citation:

W

Abstract 
1. Introduction 
2. Empathy versus apathy at the university 
3. Motivational decision making of teachers 
3. Method 
3.1. Survey characteristics and participants

3.2. Results and discussion

$$
\bar{x}=5.09
$$$$
\bar{x}=3.98
$$ 
Table 2. Expressions of students on importance (expectation) versus real application (reality) of teachers' individual approach to them

\begin{tabular}{l}
$\leq$ \\
\hline \\
$\geq$ \\
$\geq$ \\
$\geq$
\end{tabular}

\begin{tabular}{l}
$\leq$ \\
\hline \\
$\geq$ \\
$\geq$ \\
\end{tabular}

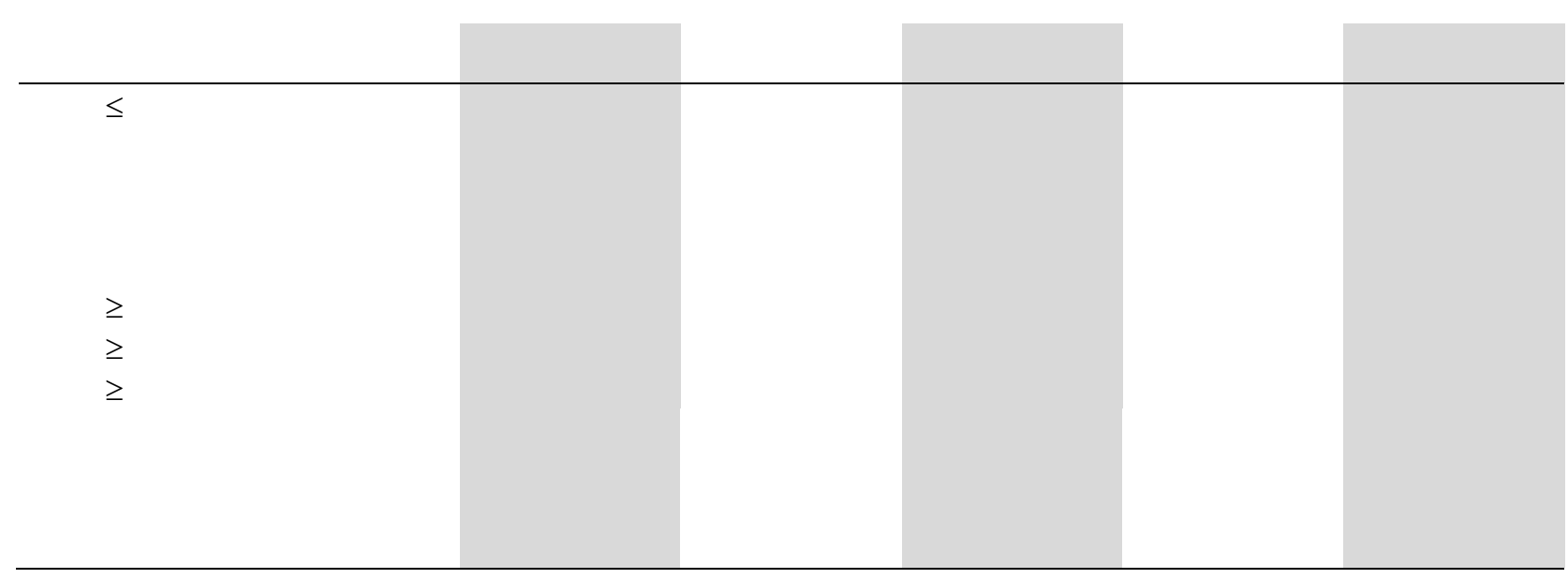


$\bar{x}=5.03$

$$
\bar{x}=3.79
$$$$
\bar{x}=4.04
$$

$$
\bar{x}=5.12
$$


4. Conclusion

accelerate.

active real reflection of a multidimensional action.

- W

- 1 
- I

Acknowledgements

\section{References}

$Q$ 
w

W

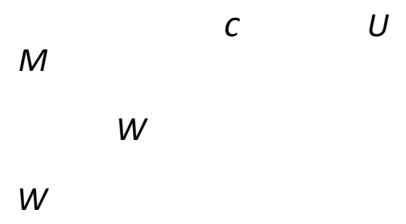

W
$w^{M}$

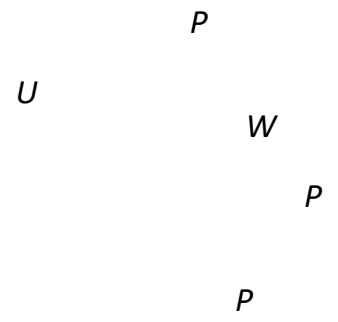

B

I

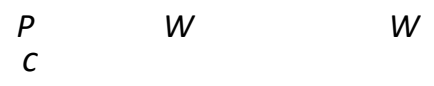

64 
D

U

P

$Q$

$U$

P I

U

w

W P

w

W W

W W 